\title{
Direct Synthesis of Highly Crystalline ZSM-5 from Indonesian Kaolin
}

\author{
Hartati Hartati1,*, Alfa Akustia Widati', Tanti Kartika Dewi', Didik Prasetyoko² \\ ${ }^{1}$ Department of Chemistry, Faculty of Science and Technology, Universitas Airlangga, \\ Kampus C Unair, Jl. Mulyorejo, Surabaya, 60115, Indonesia \\ ${ }^{2}$ Department of Chemistry, Faculty of Matematic and Natural Science, Institut Teknologi Sepuluh \\ Nopember, Keputih, Surabaya, 60115, Indonesia
}

Received: 21 st November 2016; Revised: 30th December 2016; Accepted: $18^{\text {th }}$ February 2017

\section{Abstract}

Direct synthesis of ZSM-5 from Indonesian kaolin without calcination for the formation of metakaolin was done through the addition of an alkaline solution (sodium fluoride and sodium hydroxide) and the fusion using sodium hydroxide. Crystallization was conducted through hydrothermal method at $80{ }^{\circ} \mathrm{C}$ for four days. XRD diffractogram and FTIR spectra showed that the addition of sodium fluoride solution in the ratio $\mathrm{Si} / \mathrm{Al}=100$ could produce highly crystalline ZSM-5, whereas the use of a sodium hydroxide solution and fusion process did not produce the crystalline ZSM-5. Copyright (C 2017 BCREC Group. All rights reserved.

Keywords: Kaolin; Sodium fluoride; Synthesis of ZSM-5; crystalline ZSM-5

How to Cite: Hartati, H., Widati, A.A., Dewi, T.K., Prasetyoko, D. (2017). Direct Synthesis of Highly Crystalline ZSM-5 from Indonesian Kaolin. Bulletin of Chemical Reaction Engineering \& Catalysis, 12 (2): 251-255 (doi:10.9767/bcrec.12.2.809.251-255)

Permalink/DOI: http://dx.doi.org/10.9767/bcrec.12.2.809.251-255

\section{Introduction}

ZSM-5 are widely applied as a catalysts in a variety of industrial processes and environmental protection [1,2]. Generally, the ZSM-5 are synthesized with mole ratio of $\mathrm{Si} / \mathrm{Al}$ over 5 and using $\mathrm{TPA}^{+}$cation as structure directing agent (SDA) [3]. Zhu et al. [4] have synthesized ZSM- 5 by adding tetraethylorthosilicate (TEOS) as silica source and aluminum isopropoxide as an alumina source. Some researches use natural material as silica and alumina sources for examples rectorite [5,6], rice husk ash $[7,8]$, kaolin $[9,10]$, and diatomaceous earth [11]. The use of natural materials as silica and alumina

* Corresponding Author.

E-mail: hartati@fst.unair.ac.id (Hartati, H.)

Telp.: +62-31-5922427; Fax.: +62-31-5922427 source in synthesis of zeolite is more advantageous than the commercial chemical because it is more economical.

Kaolin has been used as silica and alumina sources in synthesis of ZSM-5 through calcination of kaolin to be metakaolin in an attempt to activate of kaolin [9,10,12]. Liu et al. [12] synthesized ZSM-5 from metakaolin by adding silica and alumina, Pan et al. [9] used dealuminated metakaolin, and Hartati et al. [10] used metakaolin by addition of silica. In this research, a novel method of ZSM-5 synthesis was proposed directly without pretreatment such as calcination or the formation of metakaolin. Silica of TEOS was added to complete the mole ratio of $\mathrm{Si} / \mathrm{Al}$ in the formation of ZSM-5. 


\section{Materials and Methods}

\subsection{Materials}

Kaolin was obtained from Blitar, East Java, Indonesia; sodium hydroxide (Merck, $\geq 99 \%$ ); sodium fluoride (Merck, $\geq 99 \%$ ), tetraetilorthosilicate (TEOS) (Merck, $\geq 99 \%$ ), tetrapropylammonium hydroxide (TPAOH) (Merck, $\sim 40 \%$ ), and aquadest.

\subsection{Synthesis of ZSM-5}

In this research, we compared the method of ZSM-5 synthesis: direct synthesis of ZSM-5 from kaolin and synthesis of ZSM- 5 by preparation of kaolin through alkaline fusion with sodium hydroxide and preparation kaolin by adding sodium hydroxide solution without fusion process. Preparation of kaolin through fusion process was conducted by mixing $2.5 \mathrm{~g}$ kaolin and $3 \mathrm{~g}$ sodium hydroxide in a porcelainTeflon crucible. The mixture was calcined at $600{ }^{\circ} \mathrm{C}$ for $1 \mathrm{~h}$. The fusion was crushed in the agate mortar, and was added by $62 \mathrm{~mL}$ aquadest and stirred by magnetic stirrer. Amount of sodium hydroxide added can be adjusted with the molar ratio of expected $\mathrm{Si} / \mathrm{Al}$ [13].

Preparation of kaolin without fusion was performed by mixing $2.5 \mathrm{~g}$ kaolin with $10 \mathrm{~mL}$ of $3.2 \mathrm{M}$ sodium hydroxide. The mixture was stirred using a magnetic stirrer for 1 hour [13]. In addition, preparation of kaolin was also performed by mixing $0.8 \mathrm{~g}$ of kaolin with $18 \mathrm{~mL}$ of $0.33 \mathrm{M}$ sodium fluoride accordance with the procedures in the preparation of kaolin with sodium hydroxide solution.

Three kinds of resulted samples were then used as a material for the synthesis of ZSM-5 using methods of Eimer et al. [14] with some modifications. Some TEOS added to the prepared kaolin, and then stirred for 30 minutes at room temperature. A $10 \mathrm{~mL}$ TPAOH was added to the mixture, and then stirred for 15 hours, so that the mixture had a mole ratio as $1 \mathrm{SiO}_{2}: \mathrm{xAl}_{2} \mathrm{O}_{3}: 0,2 \mathrm{TPAOH}: 38 \mathrm{H}_{2} \mathrm{O}(1 / 2 \mathrm{x}$ is the mole ratio $\mathrm{Si} / \mathrm{Al})$ [15]. The hydrothermal process was done at $80^{\circ} \mathrm{C}$ for 4 days. The solid were then washed using a centrifuge until neutral, dried at $60^{\circ} \mathrm{C}$, and calcined at $550{ }^{\circ} \mathrm{C}$ for 7 $\mathrm{h}$ in the air, with the rate of temperature 2 $\%$ min. Table 1 show the detailed information of synthesis condition in this research.

\subsection{Characterization}

The chemical compositions of the kaolin samples were determined by X-ray fluorescence (XRF) technique conducted on a PAN analytical spectrometer Minipal 4. The FTIR spectra were obtained on a Shimadzu spectrograph 8400 S with infrared optical, in the range of wavenumber from $400 \mathrm{~cm}^{-1}$ to $4000 \mathrm{~cm}^{-1}$, a spectral resolution of $4 \mathrm{~cm}^{-1}, 45$ scans, at $20^{\circ} \mathrm{C}$. X-ray Diffraction (XRD) patterns were used to identify the phase and determine the crystallinity of the powder samples. XRD patterns were recorded using an Philips X'pert diffractometer with $\mathrm{Cu} \mathrm{Ka}$ radiation with a step scan of $0.02^{\circ}$ and counting time of $10 \mathrm{~s}$. Data were recorded in the $2 \theta$ ranges of $5-50^{\circ}$.

\section{Results and Discussion}

The chemical composition of obtained kaolin based on data from XRF is shown in Table 2. The results showed that the percentage of $\mathrm{Si}$ in kaolin is only about three times the percentage of $\mathrm{Al}$, so as to obtain a mole ratio $\mathrm{Si} / \mathrm{Al}$ to be

Table 1. Method of kaolin preparation, hydrothermal condition, and mole ratio $\mathrm{Si} / \mathrm{Al}$ in the synthesis of ZSM-5

\begin{tabular}{cclcc}
\hline No. & Sample Name & Method of preparation & Hydrothermal condition & Mole Ratio of Si/Al \\
\hline 1. & C-20 & Alkaline-treatment & $80^{\circ} \mathrm{C}, 4$ days & 20 \\
2. & C-40 & Alkaline-treatment & $80^{\circ} \mathrm{C}, 4$ days & 40 \\
3. & F-20 & Alkaline-Fusion & $80^{\circ} \mathrm{C}, 4$ days & 20 \\
4. & F- 40 & Alkaline-Fusion & $80^{\circ} \mathrm{C}, 4$ days & 40 \\
5. & F-100 & Alkaline-Fusion & $80^{\circ} \mathrm{C}, 4$ days & 100 \\
6. & N-100 & NaF-treatment & $80^{\circ} \mathrm{C}, 4$ days & 100 \\
7. & N-170 & NaF-treatment & $170^{\circ} \mathrm{C}, 1$ days & 100 \\
\hline
\end{tabular}

Table 2. Chemical composition of kaolin

\begin{tabular}{lcccccccccccccc}
\hline Element & $\mathrm{Al}$ & $\mathrm{Si}$ & $\mathrm{K}$ & $\mathrm{Ca}$ & $\mathrm{Ti}$ & $\mathrm{V}$ & $\mathrm{Cr}$ & $\mathrm{Mn}$ & $\mathrm{Fe}$ & $\mathrm{Ni}$ & $\mathrm{Cu}$ & $\mathrm{Zn}$ & $\mathrm{Eu}$ & $\mathrm{Re}$ \\
\hline$\%$ & 20.2 & 65.8 & 4.36 & 2.46 & 2.02 & 0.069 & 0.04 & 0.27 & 4.21 & 0.15 & 0.10 & 0.11 & 0.06 & 0.1 \\
\hline
\end{tabular}


used in the synthesis of ZSM-5 should be added silica.

Kaolin Blitar has highly content of quartz, as seen in X-ray diffraction in Figure 1. Preparation of kaolin was done in three different ways. The first is the conventional preparation, the addition of alkali on kaolin directly before hydrothermal process [13]. The alkali is able to break bonds and the release of $\mathrm{Si}$ and $\mathrm{Al}$ in the kaolin [16]. The second way is the preparation of kaolin with alkali fusion method [13]. Figure 1 also shows the diffractogram of Blitar kaolin before and after fusion with sodium hydroxide. Characteristic peaks of kaolin appear at $2 \theta$ around $12.31^{\circ}$ and $26.61^{\circ}$. The peaks do not appear in the diffractogram of fused kaolin. In addition, the peak at $2 \theta 20.84^{\circ}$ which is the typical peak gypsite and shows that alkaline fusion of kaolin reduction of gypsite. This is consistent with those reported by Ríos et al. [13] that the the kaolin crystal can react with alkaline at high temperatures.

The results of the synthesis of ZSM-5 with three treatment kaolin and variation mole ratio of $\mathrm{Si} / \mathrm{Al}$ is shown in Figure 2. Alkalinetreatment on the mixture with a mole ratio of $\mathrm{Si} / \mathrm{Al}=20$, followed by hydrothermally at a 80 ${ }^{\circ} \mathrm{C}$ results the transformation of kaolin into amorphous solid (C-20), while the mole ratio of 40 (C-40) did not alter the structure of kaolin, which is shown with typical peak kaolin at $12.31^{\circ}$ and $26.61^{\circ}$. The treatment of alkalinefusion on kaolin before hydrothermal led to the an amorphous solid on the mole ratio of $\mathrm{Si} / \mathrm{Al}=$ 40 and 100 (F-40 and F-100). In the mole ratio of $\mathrm{Si} / \mathrm{Al}=20(\mathrm{~F}-20)$, it results various minerals

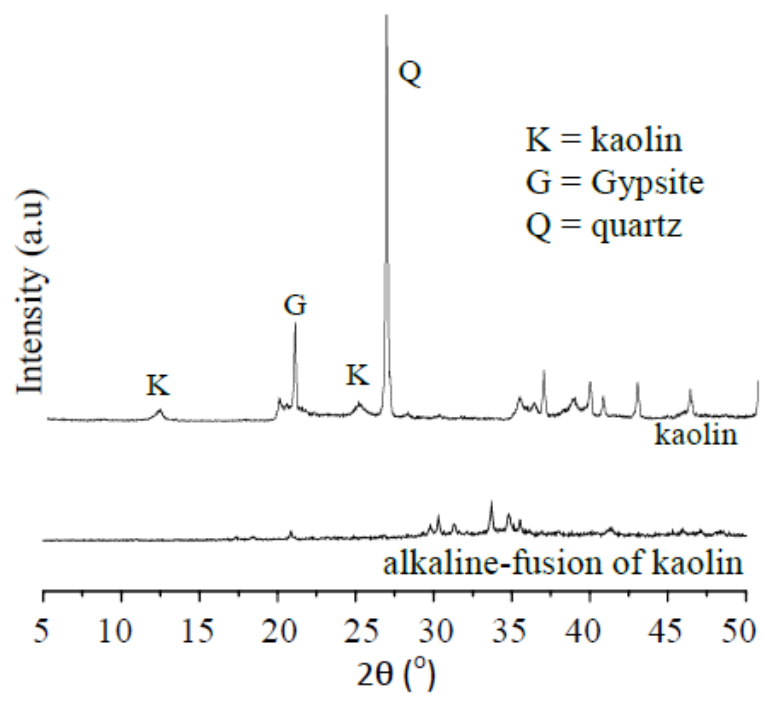

Figure 1. XRD patterns of kaolin and alkaline-fusion of kaolin like_kaolin, mordenite, natrolite, and unknown compounds. XRD patterns showed that treatment of kaolin in alkaline and alkaline-fusion at $80{ }^{\circ} \mathrm{C}$ for 4 days did not produce ZSM-5, because the absence of peaks at $2 \theta$ around 7.9; $8.8 ; 23.1 ; 24.0$; and 24.4 which correspond to the characteristic peak of ZSM- 5 .

The third way is the treatment using a solution of sodium fluoride with a mole ratio of 100 at $80{ }^{\circ} \mathrm{C}$ for 4 days $(\mathrm{N}-100)$ generates high intensity peaks at $2 \theta$ around $7.9,8.8,23.1$,

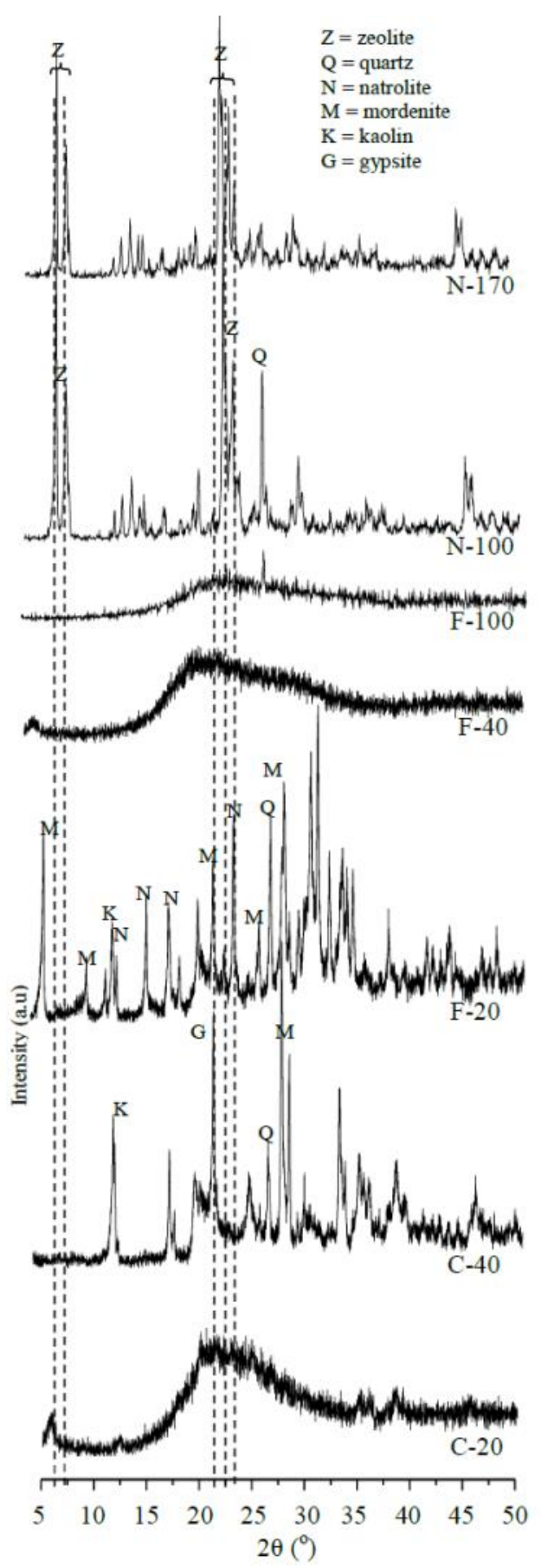

Figure 2. XRD patterns of products 
24.0 , and $24.4^{\circ}$ that indicates the typical structure of ZSM-5 with a high crystallinity [17]. This method results quartz as a by-product, proved by peaks at $2 \theta$ at around $26.59^{\circ}$. Quartz is not found when the hydrothermal temperature increased to $170{ }^{\circ} \mathrm{C}$ for 1 day (N-170). Diffractogram of sample N-100 and N-170 show high crystallinity, which can be seen from the typical sharp peak. For this phenomenon, it can be stated that in high mole ratio of $\mathrm{Si} / \mathrm{Al}$, ZSM-5 can be synthesized in lower $\mathrm{pH}$ than the $\mathrm{pH}$ of alkaline media method as reported Corma et al. [18]. The pH of mixture using sodium fluoride is only 12 , while when using alkaline-treatment, the $\mathrm{pH}$ of the mixture is 14 .

FTIR spectra of $\mathrm{C}-20$ in Figure 3 shows the absorption band at about 1200, 550, and 450 $\mathrm{cm}^{-1}$, while the $\mathrm{C}-40$ shows absorption band at around 1080, 550, and $450 \mathrm{~cm}^{-1}$. The band at around $550 \mathrm{~cm}^{-1}$ is attributed to a structuresensitive vibration caused by the double fivemember rings of the external linkages, while the absorption band at around 550 and 450 $\mathrm{cm}^{-1}$ is a typical band of the crystal structure of ZSM-5 [14]. Samples F-20, F-40, and F-100 do not show the typical bands of ZSM-5, mainly because there is no absorption band at around 550, 790, 1080, and $1200 \mathrm{~cm}^{-1}$. The FTIR spectra of sample N-100 and N-170 contain absorption band at around 1200, 1080, 790, 550, and

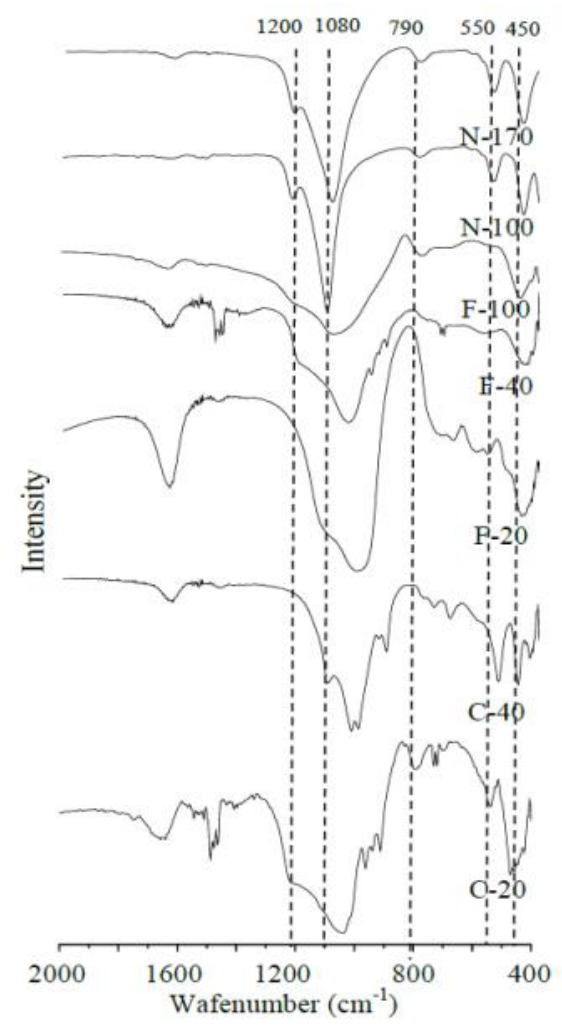

Figure 3. FTIR spectra of products
$450 \mathrm{~cm}^{-1}$. This suggests that the samples have ZSM-5 structure. The bands around 790, 1080, and $1200 \mathrm{~cm}^{-1}$ are characteristics of $\mathrm{TO}_{4}(\mathrm{~T}=$ $\mathrm{Si}, \mathrm{Al})$ tetrahedron units. The band near 790 $\mathrm{cm}^{-1}$ is assigned to the symmetric stretching of external linkages.

\section{Conclusions}

ZSM-5 with high crystallinity can be synthesized from kaolin Indonesia with quartz as impurities through treatment with the addition of sodium fluoride prior to hydrothermal process at $80{ }^{\circ} \mathrm{C}$ for 4 days or at $170{ }^{\circ} \mathrm{C}$ for 1 day with a mole ratio of $\mathrm{Si} / \mathrm{Al}=100$. Synthesis of ZSM-5 directly from kaolin by conventional treatment using sodium hydroxide solution and through alkaline fusion can not be done, because the results obtained are amorphous or other crystalline material.

\section{Acknowledgments}

The authors would like to acknowledge the Faculty of Science and Technology, Universitas Airlangga, Surabaya, Indonesia, under BOPTN research grant 2013 .

\section{References}

[1] Niwa, M., Katada, N., and Okumura, K. (2010). Characterization and Design of Zeolite Catalysts. Springer Heidelberg Dordrecht.

[2] Hagen, J., (2006). Industrial Catalysis. WileyVCH Verlag GmbH \& Co. KGaA

[3] Bellussi, G., Carati, A., Millini, R., (2010). Industrial Potential of Zeolites. In Zeolites and Catalysis Synthesis, Reactions and Applications, 473-478. Wiley-VCH Verlag GmbH \& Co. KGaA

[4] Zhu, H., Liu, Z., Kong, D., Wang, Y., Yuan, X., Xie, Z., (2009). Synthesis of ZSM-5 with Intracrystal or Intercrystal Mesopores by Polyvinyl Butyral Templating Method. Journal of Colloid and Interface Science, 331: 432438

[5] Ding, J., Liu, H., Yuan, P., Shi, G., Bao, X., (2012). Catalytic Properties of a Hierarchical Zeolite Synthesized from a Natural Aluminosilicate Mineral without the Use of a Secondary Mesoscale Template. ChemCatChem, 5: $1-13$.

[6] Liu, B., Li, C., Ren, Y.,Tan, Y., Xi, H., Qian, Y. (2012). Direct Synthesis of Mesoporous ZSM-5 Zeolite by a Dual-Functional Surfactant Approach. Chemical Engineering Journal, 210: 96-102

[7] Prasetyoko D., Ayunanda, N., Fansuri, H., Hartanto, D., Ramli, Z. (2012). Phase Trans- 
formation of Rice Husk Ash in the Synthesis of ZSM-5 without Organic Template. ITB Journal of Science, 44A(3): 250-262

[8] Atta, A.Y., Ajayi, O.A., Adefila, S.S. (2007). Synthesis of Faujasite Zeolites from Kankara Clay. Journal of Applied Sciences Research, 3: 1017-1021

[9] Pan, F., Lu, X., Wang, Y., Chen, S., Wang, T., Yan, Y. (2014). Organic Template-Free Synthesis of ZSM-5 Zeolite from Coal-Series Kaolinite. Materials Letters, 115: 5-8

[10] Hartati, H., Widati, A., Setyawati, H., Fitri, S., (2016). Preparation of Hierarchical ZSM-5 from Indonesian Kaolin by Adding Silica. Chemistry \& Chemical Technology, 10(1): 8790

[11] Aguilar-Mamani, W., García, G., Hedlund, J., Mouzon, J. (2014). Comparison between Leached Metakaolin and Leached Diatomaceous Earth as Raw Materials for the Synthesis of ZSM-5. SpringerPlus, 3: 292-302

[12] Ye, L., Xianbo, Y., Lei, Q., Jingdai, W., Yongrong, Y. (2010). In-situ Synthesis of ZSM-5 Zeolite from Metakaolin/Spinel and Its Catalytic Performance on Methanol Conversion. China Petroleum Processing and Petrochemical Technology, 12(1): 23-28

[13] Ríos, C.A., Williams, C.D., Fullen, M.A. (2009). Nucleation and Growth History of Zeolite LTA Synthesized from Kaolinite by Two Different Methods. Applied Clay Science, 42: 446-454
[14] Eimer, G.A., Diaz, I., Sastre, E., Casuscelli, G.S., Crivello, M.E., Herrero, E.R, Periente, J. (2008). Mesoporous Titanosilicates Synthesized from TS-1 Precursors with Enhanced Catalytic, Applied Catalysis A: General, 34: 77-86

[15] Gonçalves, M.L., Dimitrov, L.D., Jordão, M.H., Wallau, M., Urquieta-González, E.A. (2008). Synthesis of Mesoporous ZSM-5 by Crystallisation of Aged Gels in the Presence of Cetyltrimethylammonium Cations. Catalysis Today, 133: 69-79

[16] Zhao, H., Deng, Y., Harsh, J.B., Flury, M., Boyle, J.S. (2004). Alteration of Kaolinite to Cancrinite and Sodalite by Simulated Hanford Tank Waste and Its Impact on Cesium Retention. Clays and Clay Minerals, 52(1): 113

[17] Abrishamkar, M., Kahkeshi, F.B., (2013). Synthesis and Characterization of NanoZSM-5 Zeolite and Its Application for Electrocatalytic Oxidation of Formaldehyde over Modified Carbon Paste Electrode with Ion Exchanged Synthesized Zeolite in Alkaline Media. Microporous and Mesoporous Materials, 167: 51-54

[18] Corma, A., (2004). Towards a Rationalization of Zeolite and Zeolitic Materials Synthesis. Studies in Surface Science and Catalysis, 154(1): 25-40

Selected and Revised Papers from The 2nd International Seminar on Chemistry (ISoC 2016) (Surabaya, 26-27 July 2016) (http://chem.its.ac.id/isoc-2016/) after Peer-reviewed by Scientific Committee of ISoC 2016 and Peer-Reviewers of BCREC journal 